\title{
$\mathrm{PCR}-$ 제한효소절편길이다형성법을 이용한 $R H D 1227 \mathrm{G}>\mathrm{A}$ 및 $1222 \mathrm{~T}>\mathrm{C}$ 검출
}

김우신 · 박 건

조선대학교 의과대학 진단검사의학교실

\section{Detection of RHD 1227G >A and 1222T>C Using PCR-Restriction Fragment Length Polymorphism}

\author{
Wooshin Kim, M.D., Geon Park, M.D. \\ Department of Laboratory Medicine, College of Medicine, Chosun University, Gwangju, Korea
}

Background: DEL is an RhD variant that cannot be detected by routine serologic tests because of the extremely low expression of the RhD antigen. Detecting the common genotypes of $R H D 1227 \mathrm{G}>\mathrm{A}$ and $1222 \mathrm{~T}>\mathrm{C}$ in Korean DEL is important for safe and efficient blood transfusions. Therefore, in this study, a PCR-restriction enzyme fragment polymorphism (RFLP) method was applied to detect $R H D 1227 \mathrm{G}>\mathrm{A}$ and $1222 \mathrm{~T}>\mathrm{C}$.

Methods: DNA extracted from the blood of each segment of 56 units of RhD-negative red blood cell were used. The promoter, exon 7 and exon 9 of $R H D$, and exon 9 of $R H C E$ were amplified. The PCR products of RHD exon 7, RHD exon 9, and RHCE exon 9 were treated with the restriction enzymes HpyAV and MspI, and the RFLP patterns were observed by electrophoresis. The results of PCR-RFLP of RHD exon 9 were confirmed by PCR-direct sequencing.

Results: RHCE exon 9 was amplified in all 56 DNAs. RHD promoters, exon 7, and exon 9 were all amplified in 10 samples, $R H D$ promoter, exon 7, and exon 9 were not amplified in 38 samples, and $R H D$ promoter only was amplified in eight samples. As a result of the RHD exon 9 PCR-RFLP performed on 10 samples with all targets amplified, 10 samples were determined to be 9 samples with $1227 \mathrm{G}>\mathrm{A}$ and 1 sample with $1222 \mathrm{~T}>\mathrm{C}$. The PCR-RFLP result and the sequencing result were 100\% identical.

Conclusion: PCR-RFLP using HpyAV and MspI is a reliable and applicable method for detecting RHD 1227G $>\mathrm{A}$ and $1222 \mathrm{~T}>\mathrm{C}$ in serologically RhD negative samples. (Korean J Blood Transfus 2021;32:28-34)

Key words: RHD, DEL, Genotyping, RFLP

Received on February 16, 2021. Revised on March 22, 2021. Accepted on March 22, 2021

Correspondence to: Geon Park, M.D

Department of Laboratory Medicine, College of Medicine, Chosun University, 365 Pilmundae-ro, Dong-gu, Gwangju 61453, Korea

Tel: 82-62-220-3272, Fax: 82-62-232-2063, E-mail: creatgeon@chosun.ac.kr, ORCID: https://orcid.org/0000-0002-1414-7877

This study was supported by research fund from Chosun University (2018).

() This is an Open Access article distributed under the terms of the Creative Commons Attribution Non-Commercial License (http://creativecommons.org/licenses/by-nc/4.0) which permits unrestricted non-commercial use, distribution, and reproduction in any medium, provided the original work is properly cited.

Copyright (C) 2021 The Korean Society of Blood Transfusion 


\section{서 론}

$\mathrm{RhD}$ 혈액형의 변이형은 약 $\mathrm{D}$ 형, 부분 $\mathrm{D}$ 형과 $\mathrm{DEL}$ 형을 나눌 수 있다. 이 중 DEL형은 적혈구막 에 표현된 D 항원이 양이 극소량으로 적어 약 $\mathrm{D}$ 검 사로는 검출할 수 없으므로 흡착-용출 시험(adsorption and elution test)을 실시하여 검출한다[1]. 그 러나 일부 $\mathrm{DEL}$ 의 경우 흡착-용출 시험에도 음성 이 나올 수 있어서 이와 같은 혈청학적 검사법으 로 $\mathrm{DEL}$ 을 완전하게 검출할 수 없다고 알려져 있 다[2]. 이런 이유로 한국인 DEL을 검출하기 위해 분자검사를 널리 이용하고 있으며 한국인 $\mathrm{DEL}$ 은 대부분 $1227 \mathrm{G}>\mathrm{A}$ 와 $1222 \mathrm{~T}>\mathrm{C}$ 이므로 이를 검출 하는 여러 전략과 기법이 개발되었다[1-6].

이에 저자는 기본적인 분자검사 장비만으로 실 시가 가능하고 검사실에 적용이 비교적 쉬운 PCR제한효소절편길이다형성(restriction fragment length polymorphism, RFLP)을 적용한 RHD $1227 \mathrm{G}>\mathrm{A}$ 와 $1222 \mathrm{~T}>\mathrm{C}$ 검출법을 보고하고자 한다.

\section{대상 및 방법}

\section{1. 검체 및 $\mathrm{DNA}$ 추출}

2018년 3월부터 2020년 7월까지 수집된 RhD 음성 농축적혈구 56 단위의 각 절편에서 얻은 혈 액 $200 \mu \mathrm{L}$ 에서 LaboPass Blood Genomic DNA Isolation Kit Mini (CosmoGeneTech, Daejeon, South Korea)를 이용하여 DNA를 추출하였다.

\section{2. 대립유전자특이 PCR}

$R H D$ 프로모터, 엑손 7, 엑손 9와 RHCE 엑손 9 를 기존에 보고되거나[7] 자체 제작한 대립유전 자특이시발체(Table 1)를 이용하여 증폭하였다. 대립유전자 PCR 반응액은 2X QuestHOT Universal
Master Mix (BioQuest, Seoul, Korea) $12.5 \mu \mathrm{L}$, DNA $2 \mu \mathrm{L}$, 전방 및 후방 시발체 각 $5 \mu \mathrm{M}$ 및 증류수를 첨가하여 총 $25 \mu \mathrm{L}$ 가 되도록 하였다. Veriti 96Well Thermal Cycler (Thermo Fisher Scientific, Waltham, MA, USA)를 이용하여 다음 조건으로 $\mathrm{PCR}$ 을 진행하였다. $95^{\circ} \mathrm{C}$ 에서 15 분간 처리한 후에 $95^{\circ} \mathrm{C} 10$ 초, 다양한 온도 10 초, $72{ }^{\circ} \mathrm{C} 30$ 초씩 35 회 증폭하고 증폭산물 $5 \mu \mathrm{L}$ 를 $2 \%$ 아가로스겔에서 5 $\mathrm{V} / \mathrm{cm}$ (전압/전극간 거리)로 30 분간 전기영동을 실시하였다.

\section{HpyAV와 Mspl을 이용한 PCR-RFLP}

RHD 프로모터, 엑손 7 및 엑손 9가 모두 증폭 되어 $\mathrm{DEL}$ 이 의심되는 검체의 $R H D$ 엑손 7 와 엑손 9 그리고 $R H C E$ 엑손 9 의 각 증폭산물을 $10 \mu \mathrm{L}$ 씩 두 개의 $0.2 \mathrm{~mL} \mathrm{PCR} \mathrm{튜브로} \mathrm{나누어} \mathrm{분주하였다.}$ 분주된 각 증폭산물 중 하나에는 $\mathrm{HpyAV}(\mathrm{NEB}$, ipswich, MA, USA) $2 \mathrm{U}$ 를, 다른 하나에는 MspI (NEB) $20 \mathrm{U}$ 를 첨가한 후 $37^{\circ} \mathrm{C}$ 에서 1 시간 처리하 고 $3 \%$ 아가로스겔에서 $5 \mathrm{~V} / \mathrm{cm}$ 으로 40 분간 전기 영동을 실시하였다. HpyAV의 인식부위는 5'-CCGG$3^{\prime}$ 이며 $\mathrm{MspI}$ 의 인식부위는 5'-CCTTC-3'이다. RHD 엑손 9 의 증폭산물 $(268 \mathrm{bp})$ 은 $1227 \mathrm{G}>\mathrm{A}$ 와 1222 $\mathrm{T}>\mathrm{C}$ 변이가 없는 경우 HpyAV에 의해 잘려서 $167 \mathrm{bp}$ 와 $101 \mathrm{bp}$ 의 절편이 관찰되고, MspI에 의해 서는 잘리지 않아 $268 \mathrm{bp}$ 밴드가 관찰된다. 1227 $\mathrm{G}>\mathrm{A}$ 의 경우 HpyAV 인식부위가 3'-CTTTC-5' 로 변형되어 HpyAV에 의해 절단되지 않아 $268 \mathrm{bp}$ 의 밴드가 관찰되고, $1222 \mathrm{~T}>\mathrm{C}$ 의 경우 $\mathrm{MspI}$ 인식 부위가 5'-CCGG-3'로 변형되어 $\mathrm{MspI}$ 에 의해 절 단되어 $167 \mathrm{bp}$ 와 $101 \mathrm{bp}$ 의 절편이 관찰된다. $R H D$ 엑손 7의 증폭산물은 HpyAV에 의해 절단되지 않 으므로 $228 \mathrm{bp}$ 가 관찰되고 MspI에 의해 절단되어 $135 \mathrm{bp}$ 와 $93 \mathrm{bp}$ 가 관찰된다. $R H C E$ 엑손 9 의 증폭 산물은 $\mathrm{HpyAV}$ 에 의해 절단되어 $165 \mathrm{bp}$ 와 $105 \mathrm{bp}$ 
Korean J Blood Transfus Vol. 32, No. 1, 28-34, Apr. 2021

Table 1. Primers used in this study. Base substitutions for the intentional mismatch between the primers and template DNA are denoted by lowercase letters

\begin{tabular}{|c|c|c|c|c|c|c|c|}
\hline Name & Sequences $\left(5^{\prime}-3^{\prime}\right)$ & Specificity & $\begin{array}{l}\text { Primer } \\
\text { binding site* }\end{array}$ & $\begin{array}{l}\text { Amplicon } \\
\text { size (bp) }\end{array}$ & $\begin{array}{l}\mathrm{Ta} \\
\left({ }^{\circ} \mathrm{C}\right)\end{array}$ & Purpose & References \\
\hline RhDpromoterF & $\begin{array}{l}\text { GTATCCACTTTCCACCTCC } \\
\text { CaGC }\end{array}$ & $R H D$ & $\begin{array}{l}\text { Promoter } \\
(3918 . .3940)\end{array}$ & 259 & 65 & $\mathrm{P}$ & $\begin{array}{l}\text { This } \\
\text { study }\end{array}$ \\
\hline RhDpromoterR & $\begin{array}{l}\text { GCAGCCAACTTCCCCTGTc } \\
\text { CT }\end{array}$ & $R H D$ & $\begin{array}{l}\text { Promoter } \\
(4156 . .4176)\end{array}$ & & & $\mathrm{P}$ & $\begin{array}{l}\text { This } \\
\text { study }\end{array}$ \\
\hline RhDexon7F & $\begin{array}{l}\text { CACAGCTCCATCATGGGCT } \\
\text { ACAA }\end{array}$ & $R H D$ & $\begin{array}{c}\text { Exon } 7 \\
(39137 . .39159)\end{array}$ & 228 & 65 & $\mathrm{P}, \mathrm{R}$ & $\begin{array}{l}\text { This } \\
\text { study }\end{array}$ \\
\hline RhDexon $7 R$ & $\begin{array}{l}\text { ATTCACCGAAGCCTACTGA } \\
\text { GCAC }\end{array}$ & $\begin{array}{l}\text { RHD } \\
\text { RHCE }\end{array}$ & $\begin{array}{c}\text { Intron } 7 \\
(39342 . .39364)\end{array}$ & & & $\mathrm{P}, \mathrm{R}$ & $\begin{array}{l}\text { This } \\
\text { study }\end{array}$ \\
\hline RhDexon9F & $\begin{array}{l}\text { TGAGATACTGTCGTTTTGA } \\
\text { CACACAATAcTTC }\end{array}$ & $R H D$ & $\begin{array}{c}\text { Intron } 8 \\
(54302 . .54333)\end{array}$ & 268 & 65 & $\mathrm{P}, \mathrm{R}, \mathrm{S}$ & {$[6]$} \\
\hline RhDexon9R & $\begin{array}{l}\text { GTTTTACTCATAAACAGCA } \\
\text { AGTCAACATATATCCT }\end{array}$ & $R H D$ & $\begin{array}{c}\text { Intron } 9 \\
(54535 . .54569)\end{array}$ & & & $\mathrm{P}, \mathrm{R}, \mathrm{S}$ & [6] \\
\hline RhCEexon9F & $\begin{array}{l}\text { TGAGACACTGTCGTTTTGA } \\
\text { CACACACAAgATT }\end{array}$ & RHCE & $\begin{array}{c}\text { Intron } 8 \\
(64553 . .64584)\end{array}$ & 270 & 55 & $\mathrm{P}, \mathrm{R}$ & $\begin{array}{l}\text { This } \\
\text { study }\end{array}$ \\
\hline RhCEexon9R & $\begin{array}{l}\text { GTTTTACTCATAAACAGCA } \\
\text { AGTCAACATACATACC }\end{array}$ & RHCE & $\begin{array}{c}\text { Intron } 9 \\
(64788 . .64822)\end{array}$ & & & $\mathrm{P}, \mathrm{R}$ & $\begin{array}{l}\text { This } \\
\text { study }\end{array}$ \\
\hline
\end{tabular}

*Numbers of primer binding sites indicate ranges of primer binding sequences according to reference sequences (accession No. RHD NG_007494.1 and RHCE NG_009208.3).

Abbreviations: Ta, annealing temperature; P, PCR; R, restriction fragment length polymorphism; S, sequencing.

의 밴드가 관찰되고 $\mathrm{MspI}$ 에 의해서는 절단되지 않아 $270 \mathrm{bp}$ 밴드가 관찰된다. 이와 같이 RHD 엑 손 7 의 증폭산물은 $\mathrm{HpyAV}$ 의 음성대조와 $\mathrm{MspI}$ 의 양성대조로, $R H C E$ 엑손 9의 증폭산물은 $\mathrm{HpyAV}$ 의 양성대조와 $\mathrm{MspI}$ 의 음성대조로 이용하였다.

\section{4. 염기서열분석}

PCR-RFLP를 위한 PCR 조건과 동일하게 RHD 엑손 9을 증폭하고 증폭에 이용한 시발체(Table 1) 로 염기서열분석을 실시하였다. ExoSAP-IT ${ }^{\mathrm{TM}} \mathrm{PCR}$ Product Cleanup Reagent (Thermo Fisher Scientific) 로 정제 후 BigDye ${ }^{\mathrm{TM}}$ Terminator v3.1 Cycle Sequencing Kit (Thermo Fisher Scientific)와 ABI 3730XL (Thermo Fisher Scientific)으로 분석하였다.

\section{결 과}

\section{1. $R H D$ 프로모터, 엑손 7, 엑손 9 그리고 $R H C E$ 엑손 9 증폭 결과}

RHCE 엑손 9이 56개 DNA 모두(56/56, 100\%) 에서 증폭되었으며 $R H D$ 프로모터, 엑손 7 및 엑 손 9 이 모두 증폭된 검체는 10 개(10/56, $17.9 \%)$, RHD 프로모터, 엑손 7 및 엑손 9이 모두 증폭이 되지 않은 검체는 38 개(38/56, 67.9\%), RHD 프로 모터만 증폭되었으나 엑손 7과 엑손 9은 증폭되 지 않은 검체는 8 개 $(8 / 56,14.3 \%)$ 였다. 


\section{2. $R H D$ 엑손 7와 엑손 9 그리고 $R H C E$ 엑손 9 PCR-RFLP 결과(Fig. 1)}

RHD 프로모터, 엑손 7 및 엑손 9이 모두 증폭 된 검체 10 개 중에서 $R H D \quad 1227 \mathrm{G}>\mathrm{A}$ 로 판정된 검체는 9 개 $(9 / 56,16.1 \%)$ 였고 $R H D \quad 1222 \mathrm{~T}>\mathrm{C}$ 로 판정된 검체는 1 개( $1 / 56,1.8 \%)$ 였다. MspI과 $\mathrm{HpyAV}$ 의 성능을 평가하기 위해 함께 실시한 $R H D$ 엑손 7과 RHCE 엑손 9 PCR-RFLP 결과는 양성대조와 음성대조로서 예측한 결과와 동일하였다.

\section{3. $R H D$ 엑손 9 PCR-RFLP 결과와 염기서열 분석법 결과 비교}

동일한 $R H D$ 엑손 9 증폭산물에 대해 실시한 염기서열 결과는 $100 \%$ (10/10) PCR-RFLP 결과와 동일하였다.

\section{고 찰}

한국인에서 가장 흔한 DEL 유전형인 $1227 \mathrm{G}>$ $\mathrm{A}$ 와 $1222 \mathrm{~T}>\mathrm{C}$ 를 검출 및 감별하는 것은 안전하 고 효율적인 수혈을 위해 필요하다. 국내 수혈가 이드라인(제4판)에서는 $1227 \mathrm{G}>\mathrm{A}$ 의 경우 $\mathrm{D}$ 항원 에 노출된 후 항-D를 유발한 사례가 보고된 적이
없어서 RhD 양성 혈액제제 수혈을 이용할 수 있 다고 하였으나, Yang 등[2]은 응급상황이 아닌 경 우 원칙적으로 $1227 \mathrm{G}>\mathrm{A}$ 와 $1222 \mathrm{~T}>\mathrm{C}$ 를 포함한 모든 $\mathrm{D}$ 변이형 환자에게 $\mathrm{RhD}$ 음성 혈액제제 수 혈이 권장된다고 하였다. 실제로 Choi 등[8]은 심 장 이식 수술이 예정 중인 $R H D \quad 1227 \mathrm{G}>\mathrm{A}$ 환자 에게 $\mathrm{RhIG}$ 와 함께 $\mathrm{RhD}$ 양성 성분채집혈소판 1 단 위를 투여하고 예정된 심장이식 시점(3개월 후)에 anti-D가 검출되지 않은 것은 확인한 후 RhIG 투 여 없이 76단위의 $\mathrm{RhD}$ 양성 혈액제제를 수혈 후 1 년 이상 추적 관찰에서 anti-D가 생성되지 않은 한 사례를 보고하면서 아시아 DEL형(RHD 1227 $\mathrm{G}>\mathrm{A}$ )에게는 $\mathrm{RhD}$ 양성 혈액제제를 비응급 상황 에서도 사용하는 것을 제안하였다. 이렇듯 $\mathrm{DEL}$ $1227 \mathrm{G}>\mathrm{A}$ 의 경우 $\mathrm{DEL} 1227 \mathrm{G}>\mathrm{A}$ 혈액형 여부를 알고 있으면 $\mathrm{RhD}$ 음성 혈액제제의 수급이 어려 운 응급한 상황에서 다른 $\mathrm{RhD}$ 음성이나 $\mathrm{RhD}$ 변 이형보다 더 유연하게 $\mathrm{RhD}$ 양성 혈액제제를 이 용할 수 있는 장점이 있다.

혈청학적으로 $\mathrm{RhD}$ 음성인 한국인의 $R H D$ 유전 형의 종류와 각 빈도는 $R H D$ 전체 소실 74 75\%, $\mathrm{DEL} 13 \sim 17 \%, R H D-C E-D$ 하이브리드 $9 \sim 10 \%$ 로 알려져 있다[9]. 본 연구에서 무작위로 수집된 혈 청학적으로 $\mathrm{RhD}$ 음성인 공혈자의 56 개 검체에서

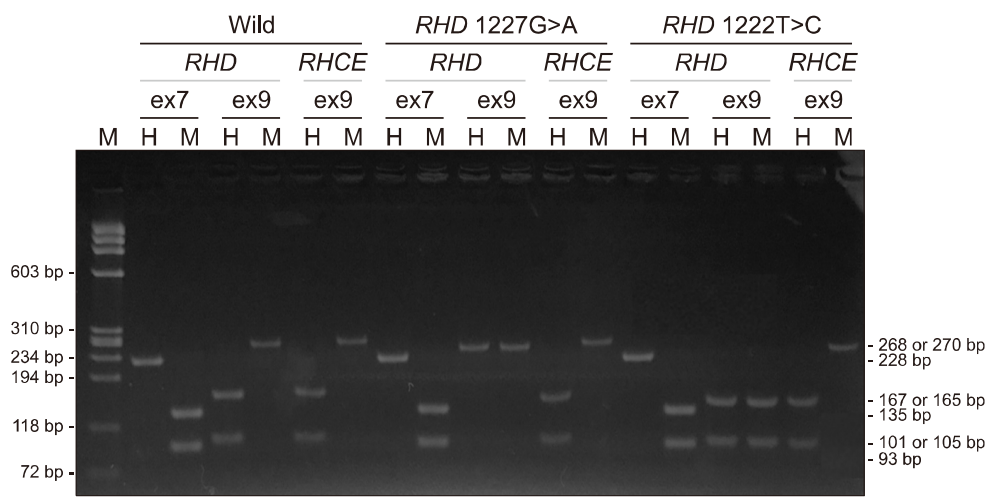

Fig. 1. PCR-RFLP patterns of $R H D$ exon 7, RHD exon 9, and RHCE exon 9 using HpyAV and MspI. Representative results are shown for a wild RhD positive, for a DEL $1227 \mathrm{G}>\mathrm{A}$, and for a DEL $1222 \mathrm{~T}>\mathrm{C}$. A weak (partial) D will show the same pattern as a wild RhD positive. Lane M, $\varphi$ X174 HaeIII digest (Takara, Shiga, Japan). Abbreviations: H, HpyAV; M, MspI. 
의 $R H D$ 유전형은 $R H D$ 전체 소실 $67.9 \%, \mathrm{DEL}$ $17.9 \%, R H D-C E-D$ 하이브리드 의심 $14.3 \%$ 였으며 기존에 보고된 결과와 유사하였다. 한국인 DEL 에서 보고된 유전변이와 각 빈도는 $1227 \mathrm{G}>\mathrm{A}$ $16.3 \%, 1222 \mathrm{~T}>\mathrm{C}$ 가 $0.9 \%$ 였고 $711 \mathrm{delC}$ 는 한 차례 증례보고가 있었다 6,10$]$. 본 연구에서 $R H D 1227 \mathrm{G}>\mathrm{A}$ 는 $16.1 \%$ 였고 $R H D 1222 \mathrm{~T}>\mathrm{C}$ 는 $1.8 \%$ 였으며 기 존 보고와 유사하였다.

$R H D$ 유전형 검사에서 염기서열분석법이 표준 검사법이지만 과정이 복잡하고 시간이 오래 걸리 므로 PCR 기법을 응용하여 여러 전략이 개발되 었다[1-6]. 이 전략들은 혈청학적 $\mathrm{RhD}$ 음성에서 $R H D$ 전체 소실을 일차적으로 배제하고 $\mathrm{DEL}$, RHD-CE-D 하이브리드 그리고 weak (또는 partial) $\mathrm{D}$ 를 선별할 수 있도록 디자인되어 있으며 $\mathrm{PCR}$ 횟수를 줄이거나 다중(multiplex) PCR을 실시하기 위해 특정 표적만을 선택적으로 증폭한다. 본 연 구에서는 $R H D$ 전체 소실과 DEL $1227 \mathrm{G}>\mathrm{A}$ 및 $1222 \mathrm{~T}>\mathrm{C}$ 를 선별 또는 검출하기 위해서 $R H D$ 프 로모터, 엑손 7 와 엑손 9 를 표적으로 선정하였다. Hong 등[6]의 연구에서는 RHD 엑손 9 와 엑손 10 을 선정하였다. $R H D$ 전체 소실에서는 $R H D$ 프로 모터와 엑손 10 를 포함한 모든 $R H D$ 표적이 증폭 되지 않으므로 $R H D$ 전체 소실을 선별하기 위해 본 연구에서는 프로모터를, Hong 등[6]의 연구에 서는 엑손 10 을 이용하였다. RHD-CE-D 하이브리 드는 RHD 프로모터는 증폭이 되나 RHD 엑손 7 과 엑손 9는 증폭되지 않는다. 야생형, weak (또는 Partial) D 그리고 RHD $1227 \mathrm{G}>\mathrm{A}$ 및 $1222 \mathrm{~T}>\mathrm{C}$ 은 $R H D$ 프로모터, 엑손 7과 엑손 9 모두 증폭된다. 본 연구에서는 대조 증폭 표적으로 RHCE 엑손 9 를 이용하여 $\mathrm{DNA}$ 의 양과 질 그리고 $\mathrm{PCR}$ 의 성 공 여부를 평가할 수 있었다.

$R H D 1227 \mathrm{G}>\mathrm{A}$ 및 $1222 \mathrm{~T}>\mathrm{C}$ 와 같은 단일염기 변이를 검출하는 기법은 매우 많으나[11,12], 최근
까지 $R H D 1227 \mathrm{G}>\mathrm{A}$ 와 $1222 \mathrm{~T}>\mathrm{C}$ 를 검출하는데 이용된 기법은 직접염기서열분석법, 대립유전자 특이PCR, 다중단일염기시발체확장반응(multiplex single-base primer extension reaction), 형광공명에 너지전이(fluorescence resonance energy transfer) 소식자를 이용하는 고해상도융해곡선분석(highresolution melting curve analysis, HRM) 등이다 [5,6]. $\mathrm{RhD}$ 음성 공혈자에서 $R H D$ 유전자 결실의 zygosity를 확인하기 위해 PCR-RFLP 기법을 이용 한 연구가 있었으나[13], RHD $1227 \mathrm{G}>\mathrm{A}$ 와 1222 $\mathrm{T}>\mathrm{C}$ 를 검출하기 위해 RFLP 기법을 이용한 것은 본 저자들이 알고 있는 한 최초 연구로 사료된다. 본 연구에서 이용한 PCR-RFLP 기법은 다른 검사 기법처럼 $\mathrm{PCR}$ 과정이 필요하나 특수 분자 검사 장비나 시약이 필요하지 않고 비교적 쉽게 실시 할 수 있으므로 검사실에 용이하게 적용할 수 있 다. 하지만 HRM 기법에 비해 상대적으로 검사 단 계가 많고 검사시간이 길다[14]. 따라서 $\mathrm{HRM}$ 을 구동할 수 있는 실시간 PCR 장비(real-time PCR instrument)를 가지고 있는 임상분자검사실에서는 $\mathrm{HRM}$ 을 이용하면 많은 검체를 신속하게 분석할 수 있을 것이다. 현재 많은 임상분자검사실에서 실시간 PCR 장비를 가지고 있으나 HRM 소프트 웨어를 별도로 구매하여 사용하는 검사실은 많지 않다. $\operatorname{Kim}$ 등[15]에 의하면 약 D검사에서 음성 및 $\mathrm{RhCE}$ 표현형 검사에서 $\mathrm{C}$ 항원 양성인 경우 $\mathrm{RHD}$ 유전형 검사를 실시할 것을 권고하고 있는데 RHD 유전형 검사의 예상 건수가 적고 $\mathrm{HRM}$ 을 실 시할 수 없는 임상검사실에서는 형광 소식자와 $\mathrm{HRM}$ 소프트웨어를 구매하여 HRM 기법을 시행 하기 보다는 PCR-RFLP 기법을 이용하여 RHD $1227 \mathrm{G}>\mathrm{A}$ 와 $1222 \mathrm{~T}>\mathrm{C}$ 를 검출하는 것이 더 효율 적일 것으로 생각된다.

DEL 표현형을 보이는 유전변이가 The Human RhesusBase에 현재 총 44개가 현재 등록되어 있 
으며[16], 이들 유전변이에는 단일염기 치환, 다중 염기 치환, 단일염기 결실, 엑손 결실, 삽입, 그리 고 하이브리드 등이 있다. 본 연구에서는 $R H D$ $1227 \mathrm{G}>\mathrm{A}$ 와 $1222 \mathrm{~T}>\mathrm{C}$ 를 검출하는 기법을 개발 하였으나 $1227 \mathrm{G}>\mathrm{A}$ 와 $1222 \mathrm{~T}>\mathrm{C}$ 이외에도 여러 변이에서 DEL 표현형을 보이므로 1227과 1222에 서 야생형을 보인 경우에는 $R H D$ 프로모터와 모 든 엑손을 PCR-염기서열분석을 하는 것이 필요 할 것으로 사료된다.

본 연구에서 혈청학적 $\mathrm{RhD}$ 음성 검체 56 개에 서 총 10 개의 $\mathrm{DEL}$ 검체를 찾았으며 $\mathrm{HpyAV}$ 과 $\mathrm{MspI}$ 를 이용하여 $1227 \mathrm{G}>\mathrm{A}$ 9개 검체와 $1222 \mathrm{~T}>\mathrm{C}$ 1 개 검체를 찾았다. $R H D \quad 1227 \mathrm{G}>\mathrm{A}$ 및 $1222 \mathrm{~T}>\mathrm{C}$ 를 검출하기 위한 $\mathrm{HpyAV}$ 와 $\mathrm{MspI}$ 을 이용하는 PCR-RFLP은 신뢰할 수 있고 적용가능한 검사 기 법으로 사료된다.

\section{요 약}

배경: DEL은 일반적인 혈청학적 검사에서는 검출되지 않을 정도로 낮은 $\mathrm{RhD}$ 항원의 표현을 하는 한 $\mathrm{RhD}$ 변이형이다. 한국인 $\mathrm{DEL}$ 에서 흔한 유전형인 $R H D \quad 1227 \mathrm{G}>\mathrm{A}$ 와 $1222 \mathrm{~T}>\mathrm{C}$ 를 검출하 는 것은 안전하고 효율적인 수혈을 위해 중요하 다. 이에 본 연구에서 PCR-제한효소절편길이다형 성법(restriction enzyme fragment polymorphism, $\mathrm{RFLP})$ 기법을 $R H D \quad 1227 \mathrm{G}>\mathrm{A}$ 및 $1222 \mathrm{~T}>\mathrm{C}$ 을 검 출위해 적용하였다.

방법: $\mathrm{RhD}$ 음성 농축적혈구제제 56 단위 각 절 편의 혈액에서 추출된 $\mathrm{DNA}$ 를 이용하였다. $R H D$ 프로모터, 엑손 7 및 엑손 9 그리고 $R H C E$ 엑손 9 를 증폭하였다. $R H D$ 엑손 7 와 엑손 9 그리고 RHCE 엑손 9 증폭산물을 제한효소 HpyAV와 MspI으로 처리하고 RFLP 패턴을 전기영동으로 관찰하였다. PCR-직접염기서열분석으로 PCR-RFLP
의 결과를 확인하였다.

결과: $R H C E$ 엑손 9 가 56 개 $\mathrm{DNA}$ 모두 증폭되 었다. RHD 프로모터, 엑손 7 및 엑손 9이 모두 증폭된 검체는 10 개, $R H D$ 프로모터, 엑손 7 및 엑손 9이 모두 증폭이 되지 않은 검체는 38 개, $R H D$ 프로모터만 증폭된 검체는 8 개였다. 모든 표 적이 증폭된 10 개 검체에 대해 실시한 $R H D$ 엑손 9 PCR-RFLP 결과 9 개 검체는 $1227 \mathrm{G}>\mathrm{A}$ 로, 1 개 검체는 $1222 \mathrm{~T}>\mathrm{C}$ 로 판정되었다. 이 PCR-RFLP 결 과와 염기서열분석의 결과는 $100 \%$ 일치하였다.

결론: 혈청학적으로 $\mathrm{RhD}$ 음성 검체에서 $\mathrm{HpyAV}$ 과 MspI를 이용한 PCR-RFLP는 신뢰할 수 있고 적용가능한 $R H D 1227 \mathrm{G}>\mathrm{A}$ 및 $1222 \mathrm{~T}>\mathrm{C}$ 을 검출 할 수 있는 방법이다.

\section{References}

1. Seo MH, Kim B, Kwon JR, Choi YS, Kim JN, Park KU, et al. Transfusion strategy and laboratory update on the DEL variant. Korean J Blood Transfus 2015;26:1-8

2. Yang HS, Chun S, Lee SA, Kwon JR, Choi YS, Kim JN, et al. Transfusion strategy of RhD-negative/variant patients in the Korean population. Lab Med Online 2017;7:89-93

3. Seo MH, Won EJ, Hong YJ, Chun S, Kwon JR, Choi YS, et al. An effective diagnostic strategy for accurate detection of $\mathrm{RhD}$ variants including Asian DEL type in apparently RhDnegative blood donors in Korea. Vox Sang 2016;111:425-30

4. Kim TY, Hong YJ, Kim MJ, Kim H, Kim TS, Park JS, et al. Recommendations regarding practical DEL typing strategies for serologically D-negative Asian donors. Transfus Med Hemother 2020;47:88-93

5. Chen JC, Lin TM, Chen YL, Wang YH, Jin 
YT, Yue CT. RHD 1227A is an important genetic marker for $\mathrm{RhD}(\mathrm{el})$ individuals. Am J Clin Pathol 2004;122:193-8

6. Hong YJ, Kim H, Song EY, Cho D, Park KU, Han KS. Development of real-time PCR and melting curve analysis for the rapid detection of DEL with RHD (c.1222T $>$ C) or RHD (c.1227G > A). Clin Lab 2016;62:1995-2000

7. Gassner C, Doescher A, Drnovsek TD, Rozman $\mathrm{P}$, Eicher NI, Legler TJ, et al. Presence of RHD in serologically D-, C/E+ individuals: a European multicenter study. Transfusion 2005;45:527-38

8. Choi S, Chun S, Seo JY, Yang JH, Cho D. Planned transfusion of D-positive blood components in an Asia type DEL patient: proposed modification of the Korean National Guidelines for Blood Transfusion. Ann Lab Med 2019;39: $102-4$

9. Kim JY, Kim SY, Kim CA, Yon GS, Park SS. Molecular characterization of D-Korean persons: development of a diagnostic strategy. Transfusion 2005;45:345-52

10. Ma T, Yu H, Jeon S, Cho D, Chun S, Shin MG. Case of D-variant from a frameshift mutation RHD 711delC. Korean J Blood Transfus

\section{9;30:168-73}

11. Ronaghi M, Langaee T. Single nucleotide polymorphisms: discovery, detection and analysis. Per Med 2005;2:111-25

12. Matsuda K. PCR-based detection methods for single-nucleotide polymorphism or mutation: real-time PCR and its substantial contribution toward technological refinement. Adv Clin Chem 2017;80:45-72

13. Matheson KA, Denomme GA. Novel 3'Rhesus box sequences confound RHD zygosity assignment. Transfusion 2002;42:645-50

14. Hashim HO, Al-Shuhaib MBS. Exploring the potential and limitations of PCR-RFLP and PCR-SSCP for SNP detection: a review. J Appl Biotechnol Rep 2019;6:137-44

15. Kim TY, Hong YJ, Kim MJ, Kim H, Kim TS, Park JS, et al. Recommendations regarding practical DEL typing strategies for serologically D-negative Asian donors. Transfus Med Hemother 2020;47:88-93

16. Wagner FF, Flegel WA. The human RhesusBase, version 2.4.2. http://www.rhesusbase.info/ [Online] (last visited on 15 March 2021) 